\title{
Enhanced Electroluminescence from a Thiophene-Based Insulated Molecular Wire
}

Gábor Méhes, ${ }^{\dagger, \$, \#}$ Chengjun Pan, ${ }^{\S, \text { Il }}$ Fatima Bencheikh,${ }^{\ddagger}$ Li Zhao, ${ }^{\ddagger}$ Kazunori Sugiyasu, ${ }^{*}{ }^{\S}$ Masayuki Takeuchi, ${ }^{\S}$ Jean-Charles Ribierre, ${ }^{*}+, \|$, and Chihaya Adachi ${ }^{*}, \dot{\dagger},+, \|, \perp$

${ }^{\dagger}$ Fukuoka i3-Center for Organic Photonics and Electronics Research (i3-OPERA), Fukuoka 819-0388, Japan

${ }^{\ddagger}$ Center for Organic Photonics and Electronics Research (OPERA), Kyushu University, Fukuoka 819-0395, Japan

${ }^{\S}$ Organic Materials Group, Polymer Materials Unit, National Institute for Materials Science, 1-2-1 Sengen, Tsukuba, Ibaraki 305-0047, Japan

'Japan Science and Technology Agency (JST), ERATO, Adachi Molecular Exciton Engineering Project, Fukuoka 8190395, Japan

${ }^{\perp}$ International Institute for Carbon Neutral Energy Research (WPI-I2CNER), Kyushu University, Fukuoka 819-0395, Japan

\section{Current affiliations}

"Laboratory of Organic Electronics, Department of Science and Technology, Linköping University, SE-601 74 Norrköping, Sweden

IDepartment of Polymer Science and Engineering, College of Materials Science and Engineering, Shenzhen University Nanhai Ave 3688, Shenzhen, Guangdong, P. R. China, 518060

\section{Corresponding Authors}

*E-mail: sugiyasu.kazunori@nims.go.jp (K. S.).

*E-mail: ribierre@opera.kyushu-u.ac.jp (J.-C. R.).

"E-mail: adachi@opera.kyushu-u.ac.jp (C. A.).

\section{Supplementary Information}

\section{Contents}

1. Experimental Methods

2. Estimation of Molecular Orientation of Neat PC12C6 Films

3. Estimation of Hole Mobilities of PC12C6, P3HT, and P3HT:PMMA

4. Optical Modelling

5. Figures S1-S7

6. Table S1

7. References 


\section{Experimental Methods}

\section{Photoluminescent Study}

Neat films were fabricated on $1 \mathrm{~mm}$ thick quartz and $0.4 \mathrm{~mm}$ thick silicon substrates, respectively, via spin-coating in an oxygen-free glove box, from tetrahydrofuran (THF) solutions at the concentration of $3 \mathrm{mg} / \mathrm{ml}$. Before deposition, the substrates were cleaned with chloroform and acetone in an ultrasonic bath. During fabrication, the rotation speed was kept at $3000 \mathrm{rpm}$ for 30 sec. Post deposition the films were baked in a glove box for 1 hour at $100{ }^{\circ} \mathrm{C}$. The thickness of the organic films was ca. $20 \mathrm{~nm}$, measured by variable angle spectroscopic ellipsometer (VASE) (M-2000U, J.A. Woollam Co.). Solutions were prepared in THF at the concentration of $1.8 \times 10^{-3} \mathrm{mg} / \mathrm{ml}$. Films were kept in a glove box prior to experiments. Absorption spectra were measured with a UV/VIS/NIR spectrophotometer (Lambda 950, PerkinElmer). Emission (PL) spectra were recorded using a spectrofluorometer (Fluoromax 4, Horiba Scientific). Photoluminescent quantum yields were measured with an absolute PL quantum yield spectrometer (C11347 Quantaurus QY, Hamamatsu Photonics), filled by nitrogen gas. The HOMO level of the films deposited on bare silicon substrates were measured using UV photoelectron yield spectroscopy (AC-3E, Riken Keiki). LUMO level of PC12C6 was approximated by subtraction of its optical energy bandgap from its HOMO value, where the optical energy bandgap was determined as the onset energy of the absorption spectrum.

\section{Electroluminescent Study}

PLEDs were fabricated on the top of glass substrates, $25 \times 25 \mathrm{~mm}$, pre-coated with a patterned indium tin oxide layer (ITO, $110 \mathrm{~nm}$ ). Prior to device fabrication, the substrates were cleaned by washing with different organic solvents under ultrasonic treatment, heated in excess of isopropanol at $235^{\circ} \mathrm{C}$, and by using ozone and UV treatment. PEDOT:PSS (Heraeus Clevios PH1000) was spincoated on top of the ITO-substrates first $\left(3000 \mathrm{rpm}, 30 \mathrm{sec}\right.$, baking for $10 \mathrm{~min}$ at $\left.200{ }^{\circ} \mathrm{C}\right)$ in air. Then, PEDOT:PSS was wiped off the substrates using a soft cotton bud soaked in isopropyl alcohol, except a square-shaped area in the center that roughly defined the device area. Next, the substrates with PEDOT:PSS were transported into an oxygen-and water free glove box, and PC12C6 was deposited with the same method as for the thin films used for the PL study, with an addition of wiping off the unnecessary material with a soft cotton bud soaked in chloroform, except the center area. Then, the substrates were transported into a high vacuum chamber without exposing them to air and oxygen. 
Next, TPBI, LiF, and Al were high vacuum-deposited at pressures $<3.8 \times 10^{-4} \mathrm{~Pa}$, where the device area was defined by shadow masks. The surface area of devices was $4 \mathrm{~mm}^{2}$ for each device. Before measurements, the devices were encapsulated with a cover glass using UV-cured resin for bonding, without exposing the devices to air. The current density-voltage-luminance $(J-V-L)$ characteristics and EL spectra were recorded by an integrated sphere coupled to a photo multichannel analyzer (Hamamatsu) and a voltage-current source-measure unit (SMU) (Keithley 2400, Keithley Instruments Inc.), both controlled by a computer.

\section{Estimation of Molecular Orientation of Neat PC12C6 Films}

The optical constants of a PC12C6 neat film spin-coated on top of silicon substrates were investigated using a VASE (M-2000U, J. A. Woollam) at different incident angles ranging from $45^{\circ}$ to $75^{\circ}$ by step of $5^{\circ}$. The anisotropic extinction constants and the refractive indexes of the film were then determined by analyzing the ellipsometry data with an analytical software (WVASE32, J. A. Woollam). The orientation order parameter $(\mathrm{S})$ was determined according to the method reported in a previous work, ${ }^{35}$ to be $S=-0.10$, calculated at $446 \mathrm{~nm}$ using the data shown in Figure $\mathrm{S} 2 . \mathrm{S}=-0.5$ if the molecules are parallel to the substrate surface, $S=0$ if the molecules are randomly oriented, and $S=1$ if the molecules are aligned perpendicular to the substrate surface. The results indicate a moderate preferential horizontal orientation of the PC12C6 spin-coated films.

\section{Estimation of Hole Mobilities of PC12C6, P3HT, and P3HT:PMMA}

Hole transporting only devices with the structure of ITO/PC12C6 or P3HT or P3HT:PMMA (70:30 wt \%)/Au were prepared to estimate the hole mobilities of the polymers using the space charge limited current $\left(j_{\text {SCLC }}\right)$ method [Ahmed 2011]. Polymer layers with thickness of around $100 \mathrm{~nm}$ were spincoated on pre-cleaned ITO glass substrates in a nitrogen-filled glove box. After the films were annealed on hot plate with the temperature of $100{ }^{\circ} \mathrm{C}$ for 1 hour in a nitrogen-filled glove box, Au electrodes with the thickness of $t=100 \mathrm{~nm}$ were deposited in a vacuum chamber under a pressure of $<4 \times 10^{-4} \mathrm{~Pa}$. The active area of the devices was $4 \mathrm{~mm}^{2}$. After the deposition of the Au electrodes, the samples were immediately encapsulated with glass lids using epoxy glue in a nitrogen-filled glove box. The current density-voltage characteristics of the samples were evaluated using a source meter (Keithley 2400, Keithley Instruments Inc.). The $J-V$ curves in Figure S2 were fitted by the equation [Ahmed 2011] 


$$
j_{S C L C}=\frac{9}{8} \varepsilon_{r} \varepsilon_{0} \mu \frac{V^{2}}{t^{3}} \exp \left(0.89 \beta \frac{\sqrt{V}}{\sqrt{t}}\right)
$$

where $\varepsilon_{\mathrm{r}}$ is dielectric constant (relative permittivity), $\varepsilon_{0}$ is permittivity of vacuum, $\mu$ is zero-field mobility, $V$ is potential of the applied electric field, and $\beta$ is a parameter that describes the strength of the field-dependent effect. We considered $\varepsilon_{\mathrm{r}}=3.5$, an average value for organic semiconductors. We arrived to the mobility value when the chosen $\beta$ parameter gave the best fit to the near-quadratic region of a $J-V$ curve.

\section{Optical Modelling}

The optical simulations were performed with SETFOS 4.2 software in the wavelength range from 380 to $800 \mathrm{~nm}$. The profile and the position of the recombination zone in the device were extracted by fitting the measured EL spectrum to an optical model. ${ }^{42}$ In this optical model the excitons are modeled as isotropic radiative dipoles driven by the multiple reflections inside the device microcavity [Chance 1975, Wan 2000]. The power radiated from a dipole at a certain wavelength is weighed by the EML emission spectrum [Lu 2002]. 


\section{Figures S1-S7}

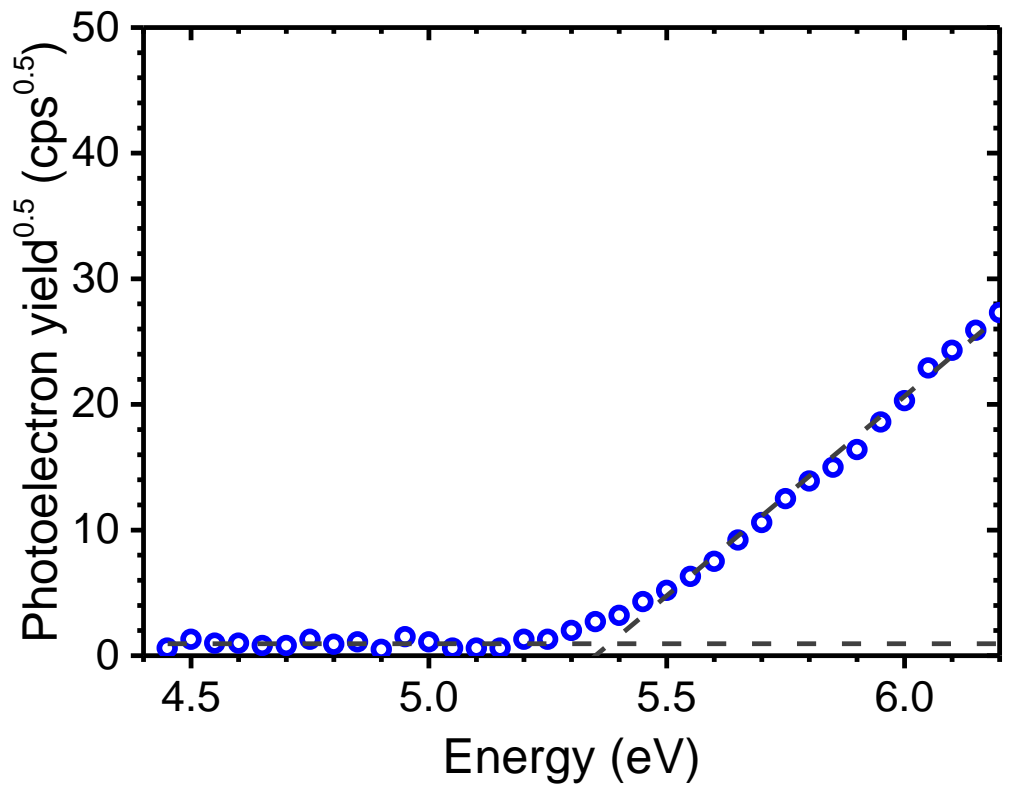

Figure S1. Ionization potential of PC12C6 films measured by photoelectron yield spectroscopy.

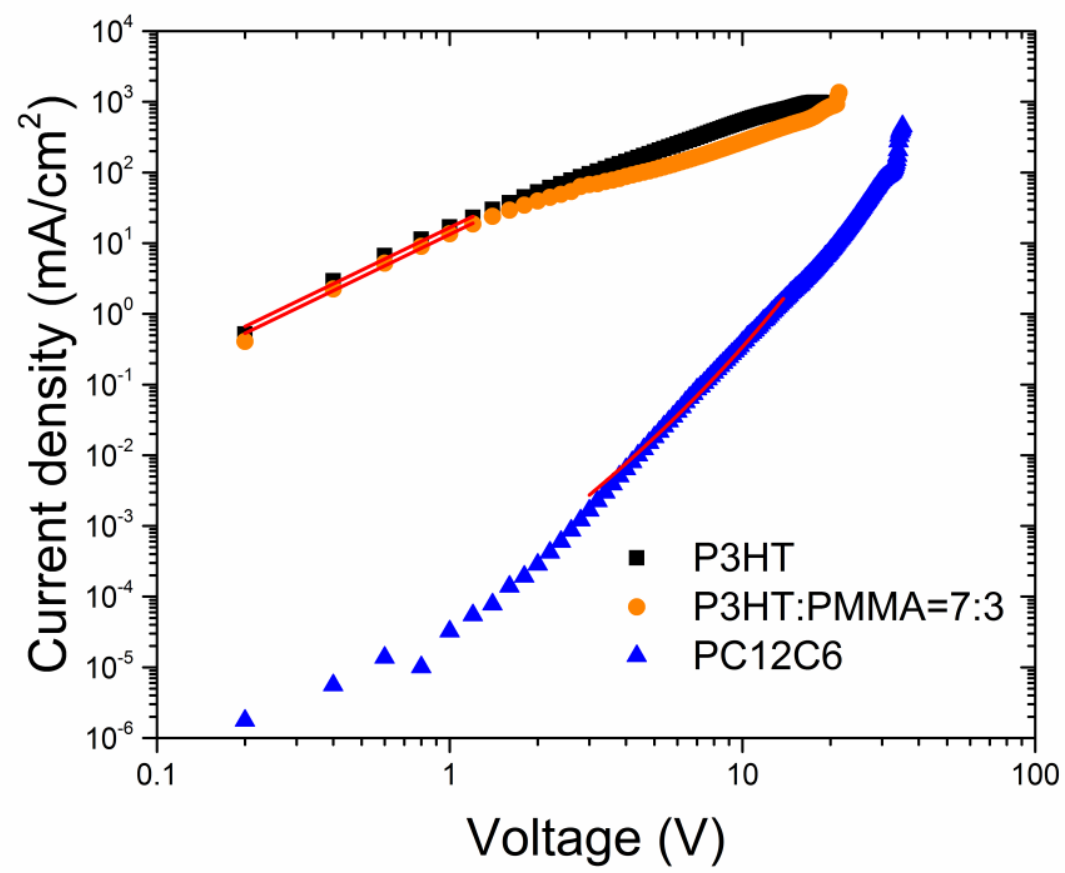

Figure S2. $J-V$ curves of hole only devices (HOD) based on PC12C6, P3HT, and P3HT:PMMA (70:30 wt \%) films. The solid lines represent the fits obtained using the SCLC method in near-quadratic regions. From these $J-V$ curves, hole mobilities of $4.7 \times 10^{-11}, 4.8 \times 10^{-5}$, and $3.8 \times 10^{-5} \mathrm{~cm}^{2} \mathrm{~V}^{-1} \mathrm{~s}^{-1}$ were obtained in PC12C6, P3HT, 
and P3HT:PMMA (70:30 wt \%), respectively, with $\beta$ parameters of $6 \times 10^{-2}, 1 \times 10^{-5}$, and $1 \times 10^{-5} \mathrm{~cm}^{1 / 2} \mathrm{~V}^{-1 / 2}$, respectively. The blend shows nearly the same hole mobility as that of the P3HT neat film, which is presumably due to a strong phase separation between the two polymers. In contrast, the hole mobility of PC12C6 film is substantially lower due to the IMW structure but the interchain quenching of the emission is strongly reduced in this material because of the good encapsulation of the light-emitting moieties. A high $\beta$ parameter in case of PC12C6 indicates a significant field-dependence compared to the other two polymers. Such a dependence can arise from shallow trapping or disorder [Blakesley 2014]. Trap states are presumably present in PC12C6 films due to the mentioned encapsulating effect.

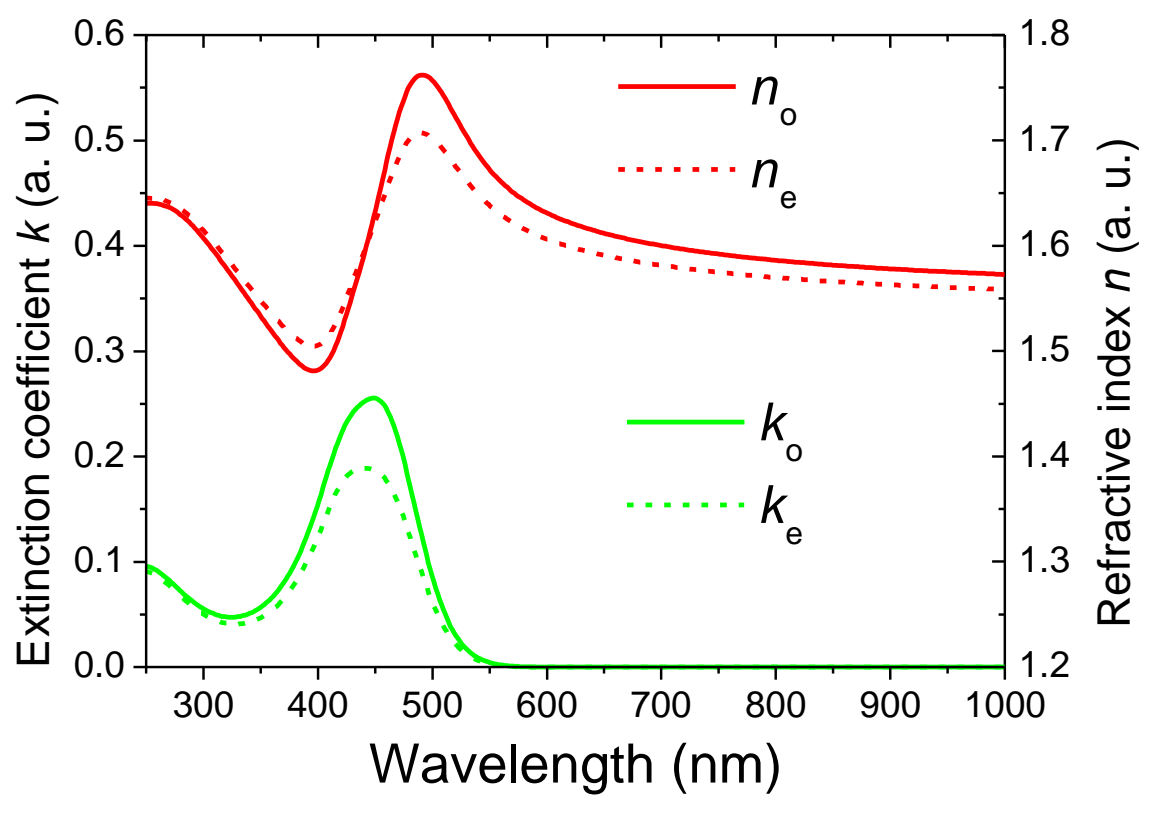

Figure S3. Optical constants ( $k$ and $n$ ) of PC12C6 neat films measured by variable angle spectroscopic ellipsometer. The film thickness was $59 \mathrm{~nm}$. The uniaxial optical anisotropy observed in the film indicates a moderate horizontal orientation of the absorption dipoles in PC12C6 films. 
a)

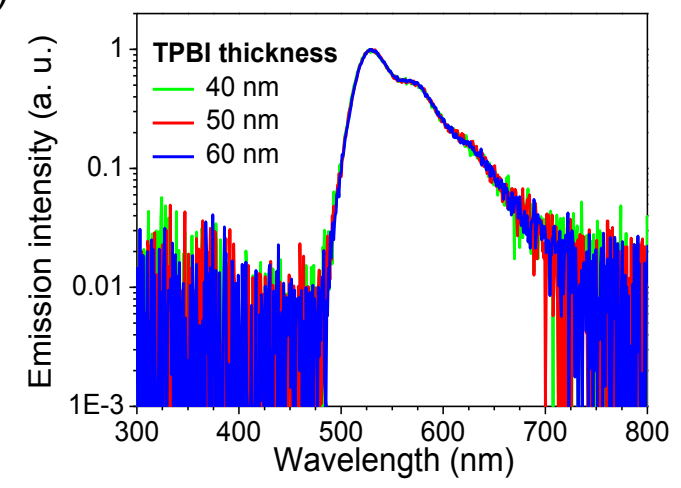

b)

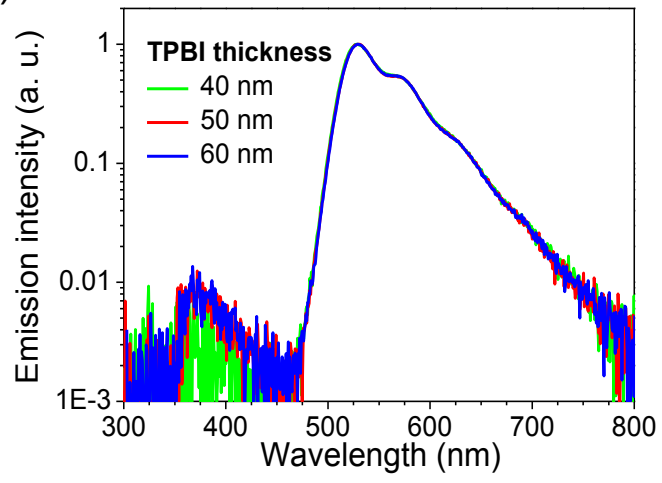

c)

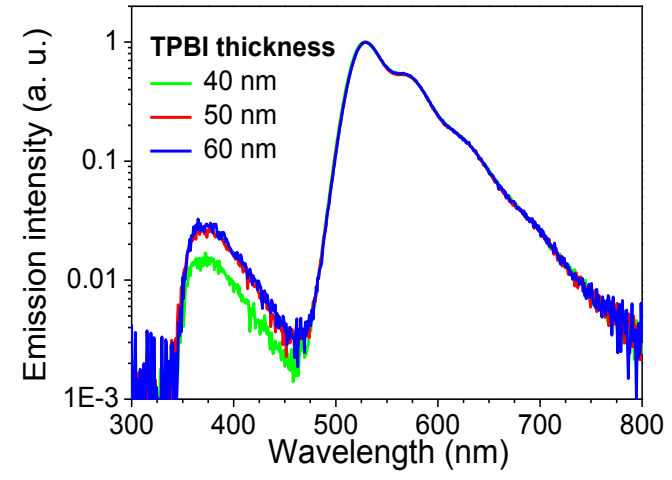

Figure S4. EL spectra of PC12C6 PLEDs measured at a) $1 \mathrm{~mA} / \mathrm{cm}^{2}$, b) $10 \mathrm{~mA} / \mathrm{cm}^{2}$, and c) $100 \mathrm{~mA} / \mathrm{cm}^{2}$ for different TPBI thicknesses.

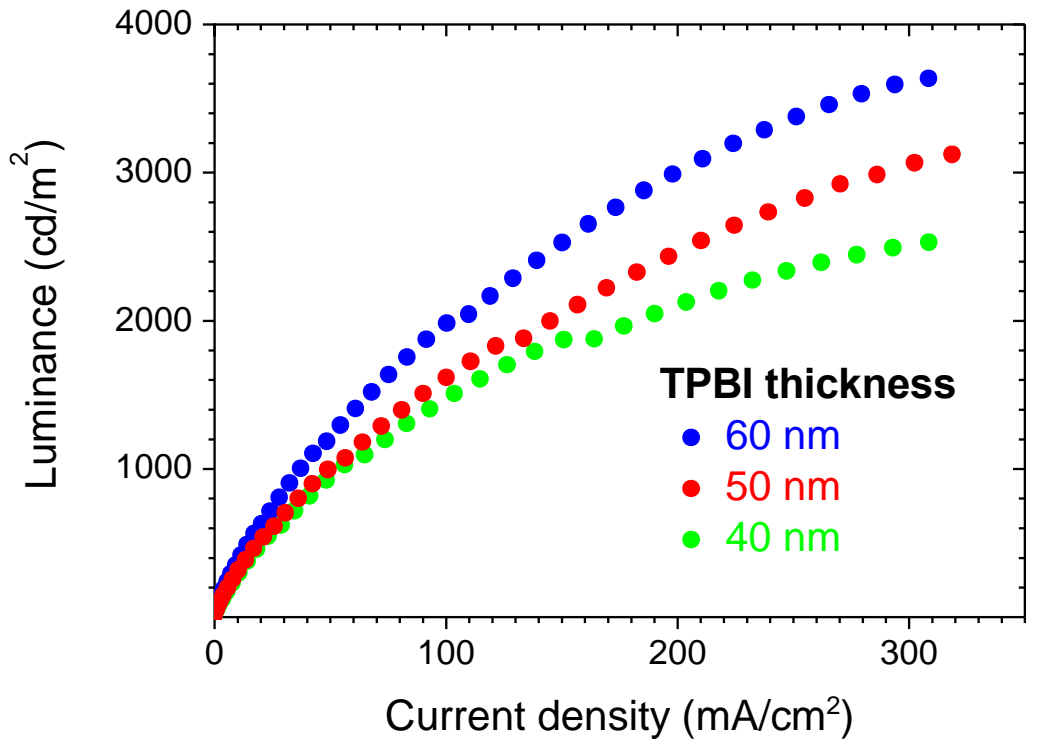

Figure S5. Luminance vs current density of the PC12C6 PLEDs-variation of TPBI thickness. 


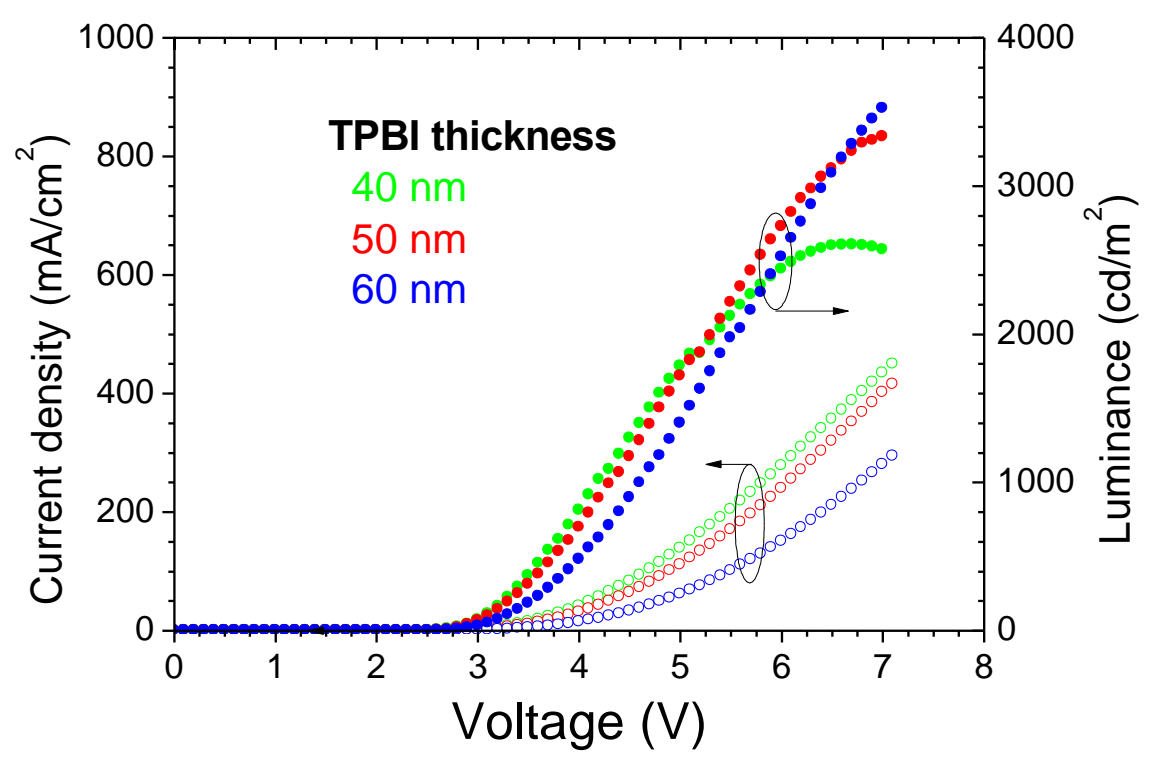

Figure S6. Current density and luminance vs voltage of the PC12C6 PLEDs-variation of TPBI thickness.
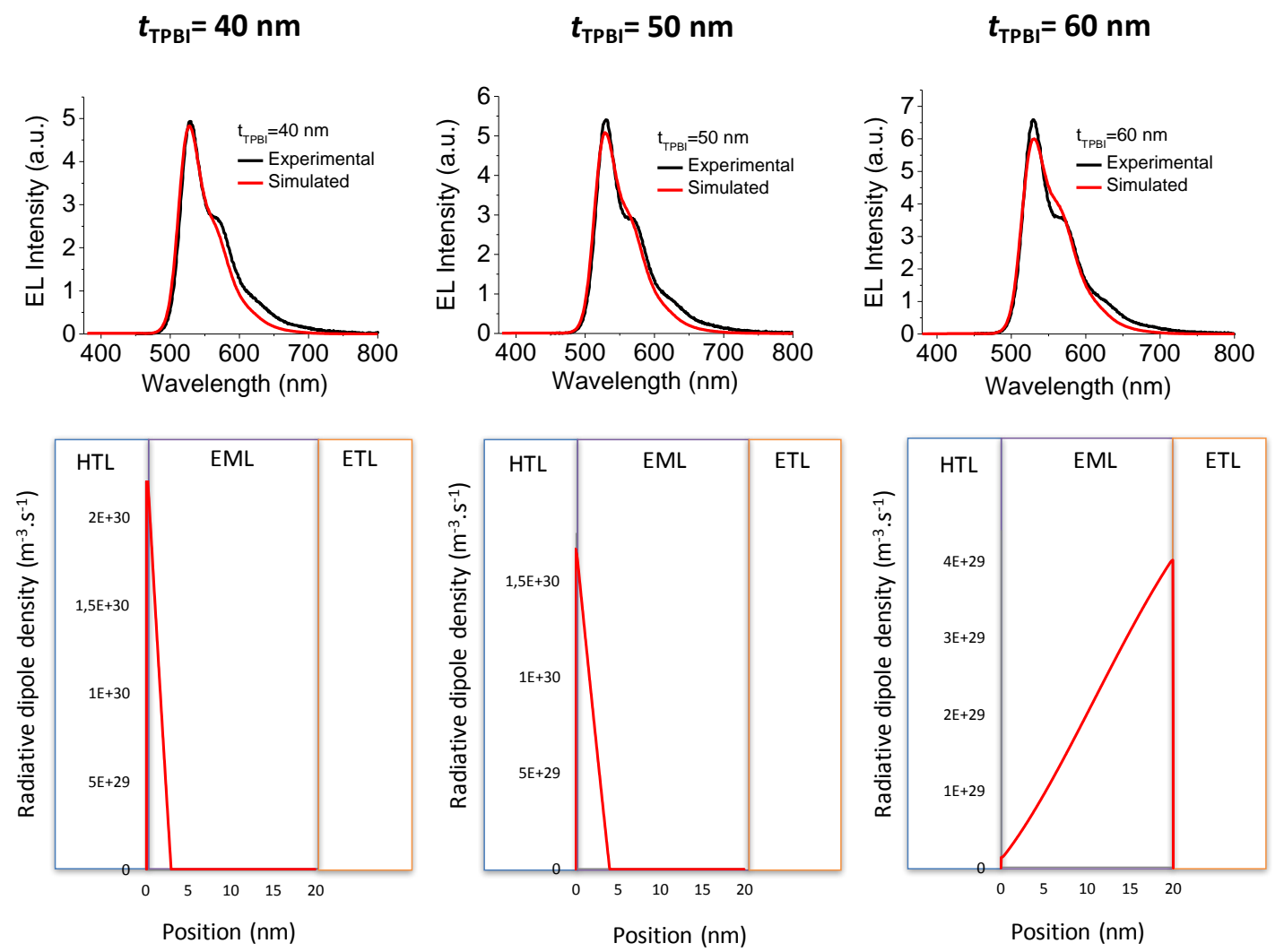

Figure S7. Optical simulations showing a) the fitting of the measured and simulated EL spectra and b) the deduced emitting (recombination) zone for $t_{\mathrm{TPBI}}=40,50$, and $60 \mathrm{~nm}$. 


\section{Table S1}

Table S1. PL and EL properties of PC12C6, comparison with some of the efficient PT-based emitters

\begin{tabular}{|c|c|c|c|c|c|c|c|c|c|c|c|}
\hline $\begin{array}{l}\text { Emitter } \\
\text { name }\end{array}$ & $\begin{array}{c}\mathrm{PT} \\
\text { functionalization }\end{array}$ & $\begin{array}{c}\Phi_{\mathrm{PL}}[\%] \\
\text { solution }\end{array}$ & $\begin{array}{c}\Phi_{\mathrm{PL}}[\%] \\
\text { film }\end{array}$ & $\begin{array}{c}\lambda_{\mathrm{PL}} \\
{[\mathrm{nm}]} \\
\text { film }\end{array}$ & $\begin{array}{c}\eta_{\text {eqe }}{ }^{\text {a) }} \\
{[\%]}\end{array}$ & $\begin{array}{c}L_{\max } \\
{\left[\mathrm{cd} / \mathrm{m}^{2}\right]}\end{array}$ & $\begin{array}{c}V_{\mathrm{ON}} \\
{[\mathrm{V}]} \\
\left(\mathrm{cd} / \mathrm{m}^{2}\right)\end{array}$ & $\begin{array}{c}\text { HOMO } \\
{[\mathrm{eV}]}\end{array}$ & $\begin{array}{c}\text { LUMO } \\
{[\mathrm{eV}]}\end{array}$ & $\begin{array}{c}\text { Assistant } \\
\text { layers }\end{array}$ & $\begin{array}{c}\text { Ref. in } \\
\text { the main } \\
\text { text }\end{array}$ \\
\hline PC12C6 & IMW & $35.4 \pm 0.1$ & $22.8 \pm 0.2$ & $\begin{array}{l}532 \\
566\end{array}$ & $\begin{array}{l}0.90 \pm 0.02 \\
1.15 \pm 0.04 \\
1.35 \pm 0.03\end{array}$ & $\begin{array}{l}2625 \pm 23 \\
3350 \pm 96 \\
3712 \pm 48\end{array}$ & $\begin{array}{l}2.4(0.11) \\
2.5(0.19) \\
2.5(0.05)\end{array}$ & -5.4 & -3.0 & $\begin{array}{l}\text { HTL/ETL40 } \\
\text { HTL/ETL50 } \\
\text { HTL/ETL60 }\end{array}$ & $\begin{array}{l}\text { This } \\
\text { work. }\end{array}$ \\
\hline T5OMe & $\begin{array}{l}\text { thiophene-S,S- } \\
\text { dioxide }\end{array}$ & - & $37 \pm 3$ & 614 & 1.29 & 200 & 1.9 & - & - & HTL & (18) \\
\hline T50Cx & $\begin{array}{l}\text { thiophene-S,S- } \\
\text { dioxide }\end{array}$ & - & - & $\sim 550$ & 0.80 & 10000 & 2.2 & -5.3 & -3.1 & $\begin{array}{c}\text { p-i-n } \\
\text { structure }\end{array}$ & (19) \\
\hline PDOPT & 3-substituted & 37 & 16 & $\begin{array}{l}606 \\
659 \\
720\end{array}$ & 0.70 & - & - & - & - & ETL & (16) \\
\hline $3 c$ & $\begin{array}{l}\text { phenylene- } \\
\text { substituted }\end{array}$ & - & 29 & 530 & 0.10 & - & 8 & -4.99 & -2.57 & $\mathrm{n} / \mathrm{a}$ & (17) \\
\hline $\begin{array}{l}\text { m-LPPP } \\
\text { and } \\
\text { PA10T }\end{array}$ & $\begin{array}{c}\text { 1wt\% PT in } \\
\text { poly(p- } \\
\text { phenylene) }\end{array}$ & - & - & $\begin{array}{c}\sim 462 \\
\sim 490 \\
580\end{array}$ & 4.20 & - & 16 & - & - & $\mathrm{n} / \mathrm{a}$ & (13) \\
\hline
\end{tabular}

a) The maximum experimental value.

\section{References}

[Ahmed 2011] Ahmed, E.; Earmme, T.; Jenekhe, S. A. (2011). New Solution-Processable Electron Transport Materials for Highly Efficient Blue Phosphorescent OLEDs. Advanced Functional Materials, $21,3889$. http://onlinelibrary.wiley.com/doi/10.1002/adfm.201100848/full

[Chance 1975] Chance, R. R.; Miller, A. H.; Prock, A.; Silbey, R. (1975). Fluorescence and energy transfer near interfaces: The complete and quantitative description of the Eu+3/mirror systems. The Journal of Chemical Physics, 63(4), 1589. http://doi.org/doi:10.1063/1.431483

[Wan 2000] Wan, W. M. V.; Greenham, N. C.; Friend, R. H. (2000). Interference effects in anisotropic optoelectronic devices. Journal of Applied Physics, 87(5), 2542. http://doi.org/10.1063/1.372216

[Lu 2002] Lu, M.-H.; Sturm, J. C. (2002). Optimization of external coupling and light emission in organic lightemitting devices: modeling and experiment. Journal of Applied Physics, 91, 595. http:// doi: 10.1063/1.1425448 
[Blakesley 2014] Blakesley, J. C.; Castro, F. A.; Kylberg, W.; Dibb, G. F. A.; Arantes, C.; Valaski, R.; Cremona, M.; Kim, J. S.; Kim, J.-S. (2014). Towards reliable charge-mobility benchmark measurements for organic semiconductors. Organic Electronics, 15, 1263.

http://www.sciencedirect.com/science/article/pii/S1566119914000469 